\title{
RANCANG BANGUN PEREKAYASAAN INDUSTRI PIPA PVC UNTUK SALURAN AIR MINUM
}

Irene Sri Sukaeni, Arum Yuniari, Sri Brataningsih Puji Lestari.

\section{ABSTRACT}

The aim this research is to find out process of production and the relation between cost, sell price and percentage of break even point. Production of capacity planned is 1.200 pipes per day; so that in a year with 288 workday, capacity produced is 345.600 pipes. The economical calculation are as follows: the total capital is fixed capital + working capital $=R p$. 1.396 .140 .000 .00 . the total production cost is variable cost a year + fixed cost a year $=R p$ 1.620.710000.00. The manufacturing cost $=R p .4 .690 .00 /$ pipe, the profit calculation before taxing is $R p, 383.770 .000 .00$ after taxing is $R p, 307.020 .000,00$ the pay oul pertod calculation consist of the percentage of profit to retum the capital (rate of return) before taxing is $27.49^{\circ} \%$ after taxing is $22,00 \%$ and the pas period before taxing 3 vear, after taxing 3 year 7 months. The break even calculation consist of break even point is $R p$ $1.031 .110 .000,00$, the percentage of break even point is $51,44 \%$ and the capacity of break even point is 177.777 pipes.

\section{INTISARI}

Penelitian ini bertujuan untuk mengetahui proses produksi dan hubungan antara biaya. harga jual dan persentase batas rugi laba. Kapasitas produksi direncanakan sebesar 1200 pipa per hari, sehingga dalam I tahun dengan 288 hari kerja kapasitas yang dihasilkan 345.600 pipa. Dari analisa ekonomi diperoleh hasil sebagai berikut : Total modal yang terdiri dari modal tetap dan modal kerja $=R p .1 .396 .140 .000,00$ biava produksi vang terdiri dari biaya tidak tetap I tahun dan biaya tetap I tahun $=R p .1 .620 .710 .000,00$. Harga pokok produksi $=R p .4 .690,00 /$ buah pipa, keuntungan sebelum pajak $R p .383 .770 .000,00$ dan sesudah pajak Rp. 307.020.000,001. Persen keuntungan untuk mengembalikan modal sebelum pajak $=27,49 \%$ dan sesudah pajak $=22,00 \%$. Waktu pengembalian modal sebelum pajak $=$ 3 tahun, sesudah pajak 3 tahun 7 bulan. Perhitungan nilai batas rugi laba $=R p$. 1.031.110,000,00 dan persentase batas rugi laba $=51,44 \%$ serta kapasitas batas rugi laba $=177.777$ buah pipa.

\section{PENDAHULUAN}

Air adalah salah satu kebutuhan pokok manusia, karena itu bukan hanya jumlah kebutuhan air yang harus terpenuhi, tetapi juga kualitas air tersebut makin hari makin penting diperhatikan karena menyangkut kesehatan manusia.

Untuk mengalirkan air dari sumbernya sampai ke konsumen dikenal berbagai macam sarana, mulai saluran dari bambu, pipa dari tanah bakar, pipa dari logam, pipa dari asbes cement dan pipa dari plastik.

Pipa yang terbuat dari bahan plastik ada bermacam-macam jenis, antara 
lain polyester, epoxy, polypropilen, polycarbonat, polyetilen, dan yang paling banyak digunakan adalah pipa dari bahan polyvinyl chlorida jenis keras atau rigid.

Pipa PVC yang beredar di pasaran kualitasnya banyak yang belum memenuhi persyaratan SII 0344 - 82 "Pipa PVC Untuk Saluran Air Minum". Sehubungan dengan hal tersebut diatas Balai Besar Penelitian dan Pengembangan Industri Barang Kulit, Karet dan Plastik telah mengadakan penelitian Peningkatan Mutu Kompon Pipa PVC yang mana sifat fisisnya telah memenubi persyaratan SII. Agar dari hasil peneitian tersebut dapat diketahui apakah harga dari pipa PVC dapat terjangkau oleh pasar di dalam negeri maupun ekspor. maka perlu dilakukan penelitian Rancang Bangun Perekayasaan Industri Pipa PVC untuk Saluran Air Minum.

\section{MATERI DAN METODE PENELITIA \\ MATERI :}

Materi yang digunakan dalam penelitian ini adalah data yang diperoleh dari studi pustaka. proses pembuatan pipa PVC pada industri dan survei pada industri pembuatan pipa PVC. Sedangkan data spesifikasi peralatan diperoleh dari distributor permesinan

\section{METODE PENELITIAN}

Data yang diperoleh diolah dengan menggunakan metode menurut Peter dan Timmerhus. 1978, sehingga dapat diketahui

- Persentase batas rugi laba

- Kapasitas pengembalian modal

- Waktu minimal untuk pengembalian modal

\section{HASIL DAN PEMBAHASAN}

a. Kegunaan dan pemasaran

Kegunaan : saluran air minum

Pemasaran : kebutuhan dalam negeri

b. Spesifikasi produk

Bentuk : pipa

Panjang : $4 \mathrm{~m}$, berat $+-1,2 \mathrm{~kg}$

Ukuran : $3 / 4 "$

Warna : abu-abu

Bahan : PVC

c. Proses Pembuatan

- Pencampuran

Semua bahan dimasukkan dalam banbury mixer dengan suhu $110 \mathrm{C}$ selama +40 menit sehingga semua bahan menjadi campuran yang homogen. Setelah campuran bahan homogen, banbury mixer dimatikan dan didapatkan hasil campuran berupa serbuk berwarna abu-abu yang halus.

- Pelletizing

Campuran berupa serbuk yang dihasilkan dari banbury mixer kemudian dimasukkan dalam corong mesin pelletizing yang telah dipanaskan hingga suhu yang diinginkan tercapai yaitu dengan pemanasan bertingkat. Hal ini dimaksudkan agar campuran yang akan dibuat pellet betul-betul masak dan tidak terjadi penyumbatan pada ekstruder.

- Pencetakan

Pencetakan pipa saluran air minum menggunakan mesin ekstruder ulir tunggal. Pellet hasil pelletizing dimasukkan dalam corong (hoper) ekstruder, kemudian didorong kedepan oleh ulir yang berputar secara terus menerus didalam sebuah silinder (barel) yang dipanaskan dan keluar melalui cetakan (die set) yang panas. Material selama dalam proses ekstrusi mengalami tekanan, gesekan dan panas yang berasal dari barel maupun die set. Pengaturan panas dan tekanan sangat mempengaruhi kualitas pipa yang akan diproduksi.

Pipa panas yang keluar dari die dan masih lembek dilewatkan pada kalibrator dengan ukuran 3/4 inci agar pipa yang dihasilkan sesuai dengan yang diinginkan dan bentuk pipa betul-betul bundar.

Pendinginan

Pendinginan dilaksanakan duz tahap yaitu dengan hembusan udara dan dengan melewatkan pipa didalam air.

Pendinginan dengan hembusan udara

Pendinginan dengan hembusan udara dimaksudkan sebagai pendinginan mula dari pipa panas yang masih lembek sehingga suhu pipa akan turun dengan pelan-pelan agar pipa tidak mendapatkan pendinginan mendadak yang dapat merusak pipa (pipa menjadi pecah/melengkung).

Pendinginan dengan air

Pendinginan dengan air ini merupakan pendinginan lanjutan setelah pipa mengalami pendinginan dengan hembusan udara.

Pipa dilewatkan pada bak berisi air yang mengalir sehingga pipa yang keluar dari bak pendingin sudah menjadi pipa yang lurus dan tidak terjadi cacat bengkok.

- Pemotongan

Pipa yang telah dingin kemudian dipotong dengan menggunakan mesin potong/gergaji yang secara otomatis dapat memotong pipa dengan panjang tertentu atau yang diinginkan $(4 \mathrm{~m})$. Pipa yang dihasilkan akan memiliki panjang yang sama. 
d. Diagram alir kualitatip

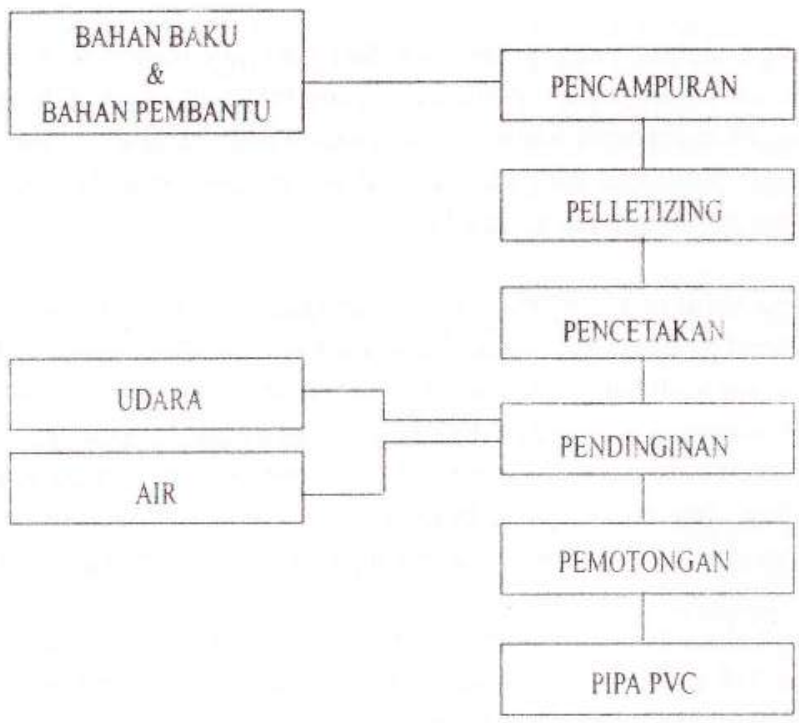

\section{PERHITUNGAN EKONOMI}

Hasil yang didapat dari perhitungan ekonomi ini akan memberikan gambaran berapa besamya modal yang dibutuhkan untuk mendirikan industri pipa PVC untuk saluran air minum. Dalam perhitungan ini, 1 tahun $=288$ hari kerja efektif.

\section{Perhitungan Modal}

1.1 Modal Tetap
a. Harga peralatan f.ob
$=$ Rp. $\quad 230,00.10^{\circ}$
b. Ongkos angkutan kapal laut, $10 \%$ (a)
c. Harga C \& F
$=$ Rp. $23,00 \cdot 10^{6}$
d. Biaya asuransi, $1 \%$ (c)
e. Harga C.I.F
$=\mathrm{Rp} \cdot \quad 253,00 \cdot 10^{\circ}$
$=\frac{\text { Rp. } \quad 2,53 \cdot 10^{6}}{255,53 \cdot 10^{6}}$
f. Biaya angkutan darat, $10 \%$ (e)
$=\mathrm{Rp} .255,53.10^{6}$
g. M.P.O $2 \%$ (a)
$=$ Rp. $25,55 \cdot 10^{\circ}$
$=$ Rp. $\quad 4,60 \cdot 10^{6}$
h. Harga alat dalam negeri
$=$ Rp. $20,80 \cdot 10^{\circ}$
i. Pemasangan alat, $10 \%(\mathrm{a}+\mathrm{h})$
$=$ Rp. 25,08.10
j. Service fasilitas \& yard improvement $10 \%(\mathrm{a}+\mathrm{h})=$ Rp. $25,08 \cdot 10^{6}$
k. Tanah dan bangunan
$=$ Rp. $368,75 \cdot 10^{6}$
1. Total biaya langsung (direct cost)
m. Engineering \& Supervisor, $15 \%$ (1)
$=$ Rp. $725,39 \cdot 10^{6}$
$=$ Rp. $\quad 108.80 .10^{6}$
n. Ongkos pemborong, $10 \%$ (1)
o. Total biaya langsung + tak langsung

p. Biaya tak terduga, $10 \%$ (a)

Jumlah Modal Tetap

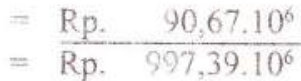

\subsection{Modal Kerja}

Kebutuhan modal kerja untuk 3 (tiga) bulan sebagai berikut
a. Bahan baku 3 bulan
$=$ Rp. $364,21.10^{6}$
b. Listrik 3 bulan
c. Gaji pegawai 3 bulan
$=$ Rp. $\quad 14,95 \cdot 10^{\circ}$
$=\frac{\text { Rp. } \quad 19,59 \cdot 10^{6}}{\text { Rp. } 398,75 \cdot 10^{6}}$

Total Modal $=$ modal tetap + modal kerja 3 bulan

Modal Tetap

Modal Kerja

$=$ Rp. $997.39 .10^{\circ}$

Total Modal

$=$ Rp. $398.75 .10^{6}$

$=\frac{\mathrm{Rp} \cdot 1.396 .14 .10^{6}}{}$

2. Perhitungan Total Biaya produksi

2.I Biaya tidak tetap (variabel cost) I (satu) tahun
a. Bahan baku 1 tahun
$=\operatorname{Rp} \cdot 1.165 .55 .10^{\circ}$
b. Iistrik I tahut
$=\frac{\text { Rp. } \quad 47.87 \cdot 10^{6}}{\text { Rp. } 1.213,42.10^{6}}$

2.2 Biaya Tetap (fixed cost) a (satu) tahun

a. Gaji I tahun $=12 \times \mathrm{Rp} \cdot 6 \cdot 530 \cdot 10$

$=\operatorname{Rp} . \quad 78,36.10^{\circ}$

b. Pemeliharaan, $2 \% \mathrm{x}$ modal

c. Bunga modal

$15 \% \times$ modal tetap

$18 \% \times$ modal kerja 3 buian

$=$ Rp. $\quad 19,94 \cdot 10^{\circ}$

$=$ Rp. $\quad 149,60 \cdot 10^{\circ}$

$=\operatorname{Rp} . \quad 71,77.10^{6}$

d. Perayusutan, $8 \%$ x motal tetap

$=\operatorname{Rp} . \quad 79,79.10^{\circ}$

e. Biaya umum, $10^{\circ} \mathrm{x}$ gaij 1 tahun

Total Biaya Produ'si = Biaya tidak tetap + biaya tetap

$=$ Rp. $1.213,42 \cdot 10^{6} \div$ Rp. $407 \cdot 29 \cdot 10^{6}$

$=$ Rp. $\quad 1.620,71.10^{6}$

3. Perhitungan Harga Pokok

Total Biaya Produksi 1 tahun

Harga Pokok $=$ Jumlah Produksi/tahun 


$$
=\frac{\text { Rp. } 1.620,71.10^{\circ}}{288 \times 1.200}
$$

\section{Perhitungan Keuntungan}

2. Hasil penjualan per tahun $(288 \times 1.200 \times$ Rp. 2800.00$)=$ Rp. $2.004,48 \cdot 10^{\circ}$

b. Total Biaya Produksi

c. Keuntungan sebelum pajak

d. Pajak perusahaan, $20 \%$

e. Keuntungan sesudah pajak

$=$ Rp. $1.620,71 \cdot 10^{\circ}$

$=$ Rp. 383.77.10

$=\operatorname{Rp} . \quad 76,75.10^{\circ}$

$=$ Rp. $307,02.10^{6}$

\section{Perhitungan Pengembalian Moda}

5.1 Persen keuntungan untuk mengembalikan modal

a. Sebeium pajak Keuntungan sebelum pajak x $100 \%$

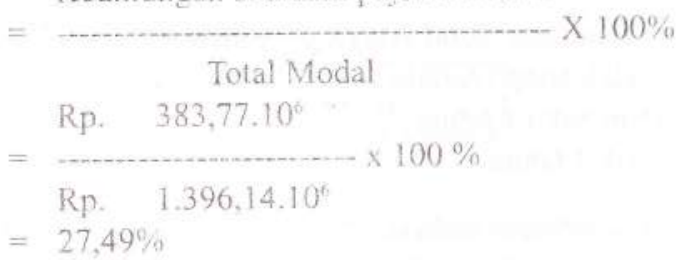

\section{Keuntungan sesudah pajak $\times 100 \%$}

b. Sesudah pajak

$$
\begin{aligned}
\text { Total Modal } & \multicolumn{1}{c}{\text { Rp. } 307,02 \cdot 10^{6}} \\
= & \text { Rp. } 1.396,14 \cdot 10^{6} \\
= & 22,00 \%
\end{aligned}
$$

5.2 Waktu pengembalian modal

\section{Total Modal}

a. Sebelum pajak

$$
=\frac{\begin{array}{c}
\text { Keuntungan Sebelum Pajak + Penyusutan } \\
\text { Rp. } 1.396,14 \cdot 10^{6}
\end{array}}{\text { Rp. } 383,77 \cdot 10^{6}+\text { Rp. } 79,79 \cdot 10^{6}} \times 1 \text { tahun }
$$

$=3$ tahun b. Sesudah pajak

Total Modal

$$
\begin{aligned}
& \begin{array}{c}
\text { Keuntungan Sesudah Pajak + Penyusutan } \\
\text { Rp. } 1 \cdot 396,14 \cdot 10^{6}
\end{array} \\
& =\frac{\text { Rp. } 307,02 \cdot 10^{6}+\text { Rp. } 79,79 \cdot 10^{6}}{=} \text { 3 th } 7 \mathrm{bl}
\end{aligned}
$$

\section{Perhitungan Batas Rugi Laba}

6. 1 Nilai Batas Rugi Laba

$$
\begin{array}{|l}
\text { Biaya Tetap } \\
1 \text { Biaya tidak tetap } \\
\begin{array}{l}
\text { Penjualan } \\
\text { Rp. } 407,29 \cdot 10^{\circ}
\end{array} \\
1-\quad \begin{array}{l}
\text { Rp. } 1.213 .42 .10^{6} \\
\text { Rp. } 2.004,48.10^{6}
\end{array}
\end{array}
$$$$
=\operatorname{Rp} \cdot 1.031,11 \cdot 10^{6}
$$

6.2 Persentase Batas Rugi Laba

Nilai Batas Rugi Laba

$$
\begin{aligned}
= & \multicolumn{1}{c}{\text { Penjualan }} \\
= & \text { Rp. } 1.031,11.10^{6} \\
= & \text { Rp. } 2.004,48.10^{6} \\
= & 51,44 \% \\
& 51,44 \\
= & 100 \% \\
= & 177.777 \text { buah }
\end{aligned}
$$

6.3 Kapasitas Batas Rugi Laba

\section{Kurva Batas Rugi Laba}

1. Biaya tidak tetap

2. Biaya tetap

3. Total Biaya Produksi

4. Total Penjualan

5. Persentase Batas Rugi Laba x 1 tahun 


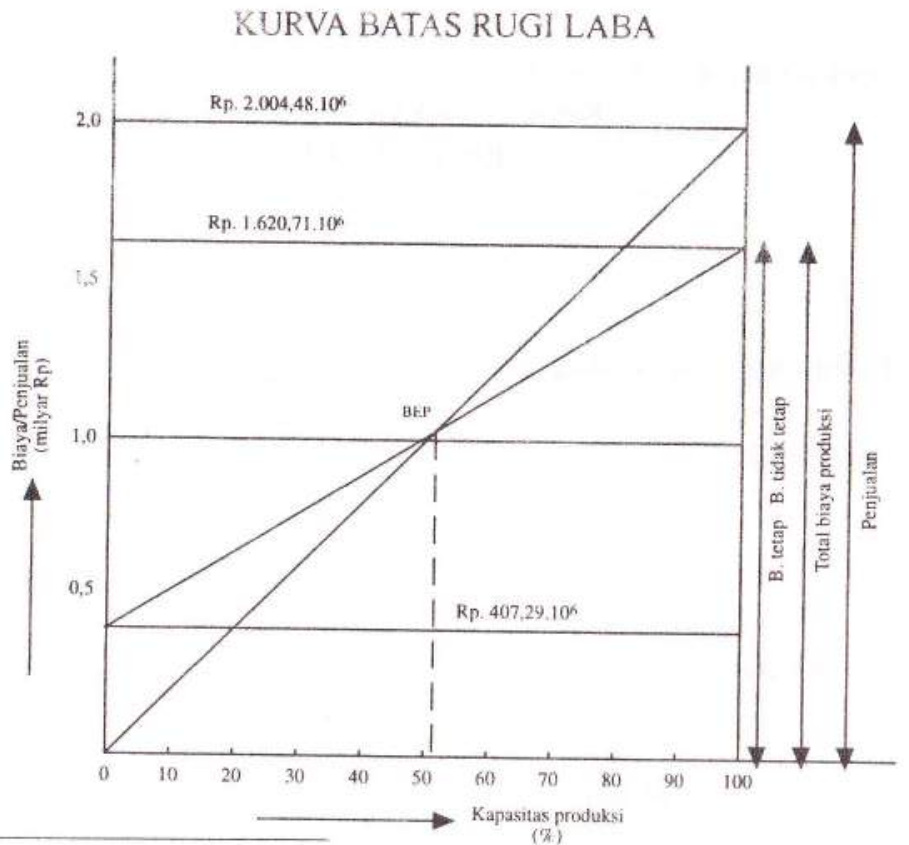

\section{KESIMPULAN}

Berdasarkan perhitungan analisis ekonomi dapat disimpulkan sebagai berikut

Dengan kapasitas produksi 1.200 buah per hari atau 345.600 buah per tahun dibutuhkan modal sebesar Rp. 1.396.140.000,00 yang terdiri dari modal tetap Rp. 997.390.000,00 dan modal kerja Rp. 398.750.000,00

- Tenaga kerja yang diserap sebanyak 37 orang

- Biaya produksi 1 tahun sebesar Rp. 1.620.700.000,00 maka diperoleh harga pokok produksi Rp. $4.690,00$ per buah.

- Apabila produk dijual dengan harga Rp. 5.800 per buah, maka keuntungan sebelum pajak $27,49 \%$ dan keuntungan sesudah pajak $22,00 \%$, waktu pengembalian modal sebelum pajak 3 tahun dan sesudah pajak 3 tahun 7 bulan, sehingga diperoleh persentase batas rugi laba $51,44 \%$.

\section{DAFTAR PUSTAKA}

1. Atmajaya, Y.Dipl.Ing, Proses dan Kualitas Pipa PVC, 1993.

2. Perry's, Chemical Engineer's Hanndbook, third edition.

3. Peter and Timmerhaus, Plant Design and Economics for chemical Engineer, Mc. Graw Hill, Kogakusha, 1978.

\section{Lampiran}

1. Bahan Baku Pertahun

Kapasitas Produksi : 1200 buah pipa panjang 4 meter, ukuran 3/4", berat $1,2 \mathrm{Kg}$.

$=1.440 \mathrm{Kg} / \mathrm{hari}$ kompon plastik

Dalam 1 tahun : 288 hari kerja efektif

\begin{tabular}{|c|c|c|c|c|c|c|c|c|c|}
\hline PVC & $=288$ & $\mathrm{x}$ & $1.136,54$ & $\mathrm{x}$ & Rp. & 3.000 & $=$ & Rp. & $981,97 \cdot 10^{6}$ \\
\hline $\mathrm{ZnO}$ & $=288$ & $\mathrm{x}$ & 6,82 & $\mathrm{x}$ & Rp. & 3.000 & $=$ & Rp. & $5,89 \cdot 10^{6}$ \\
\hline As. Stearat & $=288$ & $x$ & 11,36 & $\mathrm{x}$ & $\mathrm{Rp}$. & 6.000 & $=$ & $\mathrm{Rp}$. & $19,63 \cdot 10^{6}$ \\
\hline arat & $=288$ & $\mathrm{x}$ & 11,36 & $\mathrm{x}$ & Rp. & 5.000 & $=$ & Rp. & $16,35 \cdot 10^{6}$ \\
\hline $\mathrm{BaCdZn}$ & $=288$ & $\mathrm{x}$ & 6,82 & $x$ & Rp. & 13.000 & $=$ & & $25,53 \cdot 10^{6}$ \\
\hline Pigmen & $=288$ & $\mathrm{x}$ & 5,68 & $\mathrm{x}$ & & 15.000 & $=$ & & $24,53.10^{6}$ \\
\hline $\mathrm{ABS}$ & $=288$ & $\mathrm{x}$ & 34.10 & $x$ & & 5.000 & $=$ & & $49,10.10^{\circ}$ \\
\hline $\mathrm{aCO} 3$ & $=288$ & $\mathrm{x}$ & 227,32 & $\mathrm{x}$ & $\begin{array}{l}\mathrm{Rp} \\
\text { Jumlat }\end{array}$ & 650 & $\begin{array}{l}= \\
=\end{array}$ & $\frac{R p}{R p .}$ & $\frac{42,55 \cdot 10^{6}}{165,55 \cdot 10^{6}}$ \\
\hline
\end{tabular}

\section{Utilitas Pertahun}

Kebutuhan listrik tiap hari : 1.413 Kw dimana tiap Kw taripnya Rp. 117,5, dan harga biaya beban tiap bulan Rp. 5.060

Dalam : tahun : 288 hari kerja efekti

Biaya listrik pertahun

$(288 \times 1.413 \times \operatorname{Rp} .117,5)+(12 \times \operatorname{Rp} .5 .060)=\operatorname{Rp} .47,87.10^{6}$

Tanah dan Bangunan

Luas Tanah: $1500 \mathrm{~m}$

Harga Tanah: Rp. 150.000/m

Jumlah harga tanah $=$ Rp. $100.000 \times$ Rp. $1.500=$ Rp. $150 \cdot 10^{6}$

\section{Bangunan}

Luas bangunan pabrik : $875 \mathrm{~m}$

Harga bangunan

$=$ Rp. $250.000 / \mathrm{m}$

Jumlah harga bangunan $=875 \times$ Rp. $250.000=R p .218,78.10^{6}$

Total tanah dan bangunan $=$ Rp. $150 \cdot 10+$ Rp. $218,75 \cdot 10^{6}$

$=$ Rp. $368,75 \cdot 10^{6}$ 


\section{Perhitungan Modal Kerja 3 Bulan}

3. Bahan Baku

Dalam 1 tahun : 288 hari kerja efektif

\begin{tabular}{|c|c|c|c|c|c|c|c|c|}
\hline PVC & $=90$ & $x$ & $1.136,54$ & $\mathrm{x}$ & Rp. 3.000 & $=$ & $\mathrm{Rp}$. & $306,86.10^{\circ}$ \\
\hline $7 \mathrm{nO}$ & $=90$ & $x$ & 6,82 & $\mathrm{x}$ & Rp. 3.000 & $=$ & Rp. & $1,84 \cdot 10^{6}$ \\
\hline As. Stearat & $=90$ & $x$ & 11,36 & $\mathrm{x}$ & Rp. 6.000 & $=$ & Rp. & $6,13 \cdot 10^{6}$ \\
\hline Ca. Stearat & $=90$ & $\mathrm{x}$ & 11,36 & $\mathrm{x}$ & Rp. 5.000 & $=$ & Rp. & $5,11 \cdot 10^{6}$ \\
\hline $\mathrm{BaCdZn}$ & $=90$ & $x$ & 6,82 & $\mathrm{x}$ & Rp. 13.000 & $=$ & Rp. & $798.10^{6}$ \\
\hline Pigmen & $=90$ & $x$ & 5,68 & $\mathrm{x}$ & Rp. 15.000 & $=$ & Rp. & $7,66 \cdot 10^{6}$ \\
\hline $\mathrm{ABS}$ & $=90$ & $x$ & 34,10 & $x$ & Rp. 5.000 & $=$ & $R p$. & $15,34.10^{6}$ \\
\hline $\mathrm{CaCO}_{3}$ & $=90$ & $x$ & 227,32 & $x$ & R.p. 650 & & Rp. & $13,29.10^{6}$ \\
\hline
\end{tabular}

b. Gaji Pegawai 3 Bulan

$3 \times$ Rp. $6.530 .000=$ Rp. 19.590 .000

c. Kebutuhan Listrik Untuk 3 Bulan

Penggunaan listrik tiap hari sebesar $1.413 \mathrm{Kw}$ dengan tarip Rp. 117,5, dan biaya beban tiap bulan Rp. 5.060

Biaya Listrik $=(90 \times \mathrm{Rp} .1175 \times 1.413)+(3 \times \mathrm{Rp} .5 .060)$

$=$ Rp. $14,95.10$

\section{. Jumlah Karyawan dan Gaji Karyạwan}

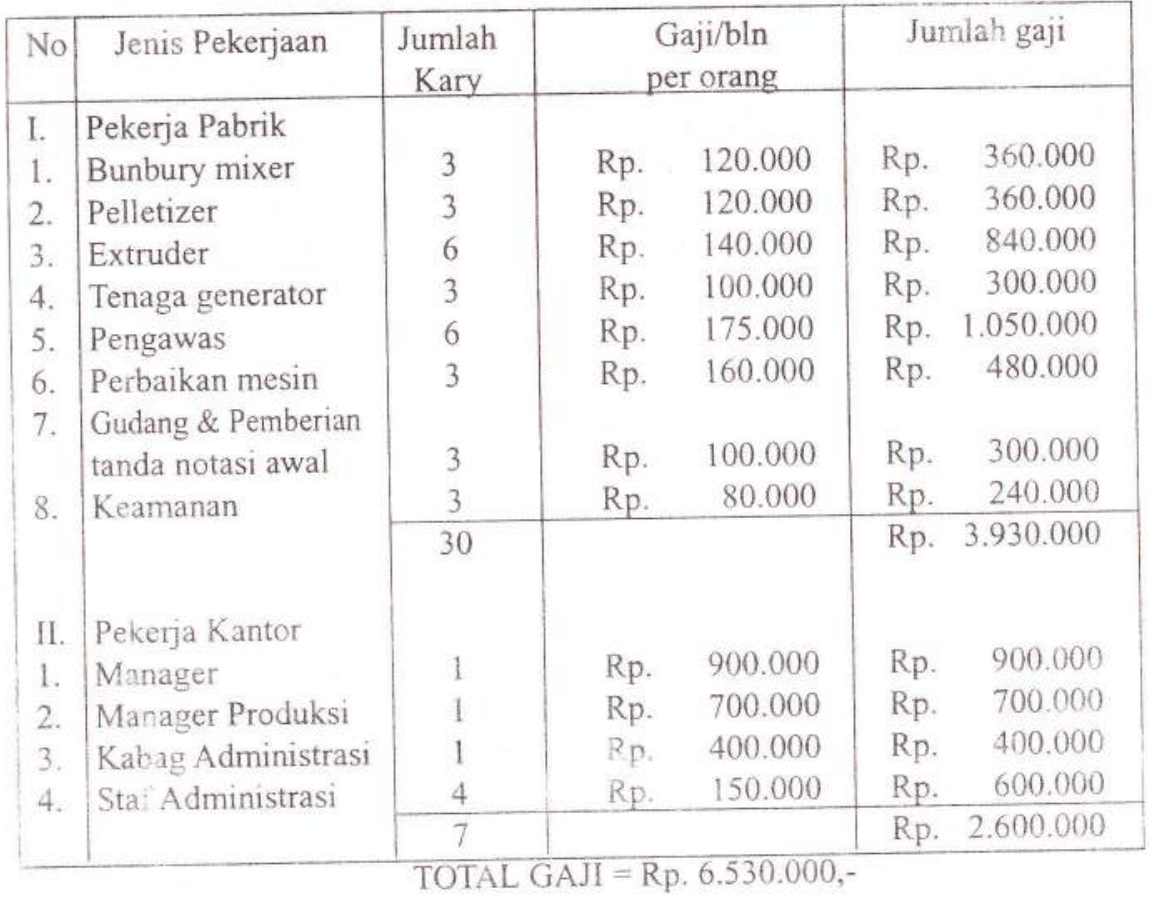

\section{Peralatan}

Tabel 1 : Harga Peralatan Impor

\begin{tabular}{|l|l|c|c|c|}
\hline No. & \multicolumn{1}{|c|}{ Nama Alat } & Jumlah & \multicolumn{1}{|c|}{ Harga/unit } & Harga \\
\hline 1. & Bantury mixer & 1 & Rp. 30.000 .000 & Rp. 30.000 .000 \\
2. & Niesin Pelletizer & 1 & Rp. 20.000 .000 & Rp. 20.000 .000 \\
3. & Mesin extruder & & & \\
& Lengkio dengan die & 2 & Rp. 90.000 .000 & Rp. 180.000 .000 \\
\cline { 4 - 5 } & & & & Rp. 230.000 .000 \\
\hline
\end{tabular}

Tabel 2: Harga Peralatan

\begin{tabular}{|l|l|c|rr|rr|}
\hline No. & \multicolumn{1}{|c|}{ Nama Alat } & Jumlah & \multicolumn{2}{|c|}{ Harga/unit } & \multicolumn{2}{|c|}{ Harga } \\
\hline 1. & Mesin pemotong & 2 & Rp. & 5.000 .000 & Rp. 10.000 .000 \\
2. & Generator & 1 & Rp. 10.000 .000 & Rp. 10.000 .000 \\
3. & Pompa & 2 & Rp. 400.000 & Rp. & 800.000 \\
\cline { 5 - 6 } & & & & & Rp. 20.800 .000 \\
\hline
\end{tabular}

